\title{
Pengaruh Harga, Kualitas Pelayanan dan Lokasi pada Laguna Family Karaoke di Sungai Penuh
}

\author{
Edia Satria \\ Sekolah Tinggi Ilmu Ekonomi Sakti Alam Kerinci \\ Correspondence email: ediasatria@yahoo.co.id
}

\begin{abstract}
This research was conducted to find out (1) The effect of Prices on Customer Satisfaction at Laguna Family Karaoke In Sungai Penuh. (2) The influence of Service Quality on Customer Satisfaction at Laguna Family Karaoke In Sungai Penuh. (3) The influence on customer Satisfaction at Laguna Family Karaoke In Sungai Penuh. (4) The influence of Price, Service Quality and Location simultaneously on Customer Satisfaction at Laguna Family Karaoke In Sungai Penuh. This research is quantitative research. The population in this research is consumers at Laguna Family Karaoke in 2019. The sampling technique used in this research was accidental sampling. The sample in this research was 80 consumers in Laguna Family Karaoke. Data collection techniques using a questionnaire. Validity test using value corrected item total correlation. Reliability test using alpha cronbach. Data analysis technique use multiple linear regression tests. Research result show that : (1) there is a positive influence between price and customer satisfaction at Laguna Family Karaoke In Sungai penuh this is proven from $t_{\text {hitung }}>$ dari $t_{\text {tabel }}$ which one 7,456 $>$ 2,021 and significant 0,000 <0,05. (2) There is no positive influence between service quality on customer satisfaction at Laguna Family Karaoke In Sungai Penuh this is proven from $t$ hitung $<$ dari $t_{\text {tabel }}$ which one $-0,918<2,021$ and significant 0,363 > 0,05. (3) there is a positive influence between location and customer satisfaction at Laguna Family Karaoke In Sungai Penuh this is proven from $t_{\text {hitung }}<$ dari $t_{\text {tabel }}$ which one $-2,371>2,021$ and significant 0,020<0,05. (4) there is a positive influence between prices, service quality and location to customer satisfaction at Laguna Family Karaoke In Sungai Penuh this is proven from oleh $f_{\text {hitung }}>$ $f_{\text {tabel }}$ that is $24,686>2,58$ dan signifikan $0,000<0,05$.
\end{abstract}

Keywords : Price, Service Quality, Location, Customer Satisfaction

\section{Pendahuluan}

Pada era globalisasi saat ini dunia usaha berkembang dengan sangat pesat, salah satunya bisnis dibidang hiburan. Banyaknya usaha yang bermunculan mengakibatkan peningkatan jumlah usaha yang bersifat sejenis menyebabkan persaingan yang semakin ketat. Maka untuk menghadapi situasi dan keadaan yang demikian, pengusaha harus mampu serta cermat dan tanggap dalam mengambil keputusan agar usaha yang didirikannya dapat berkembang dengan baik. Pelaku usaha dituntut harus bisa mempertahankan pasar dan memenangkan persaingan. Dalam memenangkan persaingan perusahaan harus mampu memahami kebutuhan dan keinginan konsumennya. Dengan memahami kebutuhan dan keinginan konsumen, maka akan memberikan masukan penting bagi perusahaan untuk merancang strategi pemasaran agar dapat menciptakan kepuasan bagi konsumennya dan dapat bertahan dalam bersaing dipasar. Perhatian terhadap kepentingan konsumen dengan cara melihat kebutuhan dan keinginan serta kepuasan atas pelayanan menjadi faktor kunci untuk keberhasilan suatu usaha ditengah iklim persaingan yang semakin ketat ini. Oleh karena itu, perusahaan dituntut untuk dapat memberikan sesuatu berharga dan dapat memberikan kesan yang mendalam bagi konsumen adalah memberikan kepuasan melalui kinerjanya yang sesuai dengan kualitas produk dan jasa yang ditawarkan.

Seiring perkembangan zaman kebutuhan manusia terus bertambah. Membuat masyarakat memiliki aktivitas dan rutinitas yang cukup kompleks. Rutinitas tersebut membuat masyarakat merasa jenuh dan lelah. Hal tersebut mendorong mereka untuk mengalihkan perhatian dan melupakan suasana yang dapat membuat mereka lebih rileks. Kebutuhan untuk rileks tersebut menjawab dengan timbulnya bisnis hiburan yang sekarang banyak hadir ditengah masyarakat. Salah satu alternatif hiburan untuk masyarakat tersebut adalah karaoke. Tempat tersebut memungkinkan orang untuk sejenak melepaskan dan melupakan kejenuhannya dengan cara bernyanyi dan bersosialisasi dengan rekan atau kerabat. Perkembangannya yang pesat telah menjadikan karaoke sebagai trend lifestyle masa kini. Beragam konsep hiburan karaoke ditawarkan untuk menarik minat masyarakat salah satunya pada tempat karaoke dengan nama Laguna Family Karaoke di Sungai Penuh. Laguna Family Karaoke yang merupakan salah satu tempat karaoke yang cukup digemari di Sungai Penuh. Laguna family Karaoke bertempat di Pondok Tinggi tepatnya di Jalan Depati Parbo desa Koto Lebu. Karaoke ini menawarkan beberapa jenis paket karaoke yang bisa dipilih oleh konsumen yaitu Small Room, Up Small Room dan Medium Room. Selain jenis produk atau jasa yang beragam fasilitas juga diperhatikan oleh pemilik karaoke ini.Terdapat beberapa pilihan tempat karaoke yang berada, disekitar Laguna Family Karaoke banyak hal yang menjadi bahan pertimbangan konsumen untuk sampai pada keputusan memilih karaoke tertentu. Pihak manajemen Laguna Family Karaoke berusaha untuk memenuhi kriteria yang menjadi bahan pertimbangan konsumen, baik harga, kualitas pelayanan maupun lokasi sehingga dapat memberikan kepuasan bagi konsumennya. Jika hal tersebut diabaikan, maka 
akan terjadi kesenjangan antara keinginan (harapan) konsumen terhadap harga, kualitas pelayanan serta lokasi yang ada di Laguna Family Karaoke. Oleh karena itu berhasil tidaknya Laguna Family Karaoke dalam berkomunikasi dengan para konsumen tergantung pada harga yang terjangkau, kualitas pelayanan yang terbaik dan lokasi yang mudah

\section{Metode}

Penelitian ini adalah penelitian kausal komperatif yaitu penelitian yang bertujuan untuk mengetahui kemungkinan adanya hubungan sebab akibat berdasarkan atas pengamatan terhadap akibat yang ada. Kemudian mencari faktor yang diduga menjadi penyebabnya, melalui pengumpulan data dengan melakukan perbandingan diantara datadata yang terkumpul/diteliti. Adapun variabel yang digunakan adalah variabel bebas yaitu harga, kualitas pelayanan dan lokasi sedangkan variabel terikat yaitu kepuasan konsumen. Waktu penelitian ini dilakukan pada kurun waktu 31 Januari - 27 Februari 2019. Dalam penelitian ini jenis data yang digunakan adalah data primer dan data sekunder. Data primer merupakan data Data primer secara khusus dikumpulkan oleh peneliti untuk menjawab penelitian yang berasal dari sumber asli atau pertama (Narimawati 2008). Data sekunder menurut Sugiyono (2008) Data sekunder merupakan sumber data yang tidak langsung memberikan data kepada pengumpul data. Data yang digunakan dalam penelitian ini adalah data primer dan data sekunder dimana data primer data yang di dapat dari tempat penelitian yaitu konsumen yang menggunakan jasa Laguna Family Karaoke Di Sungai Penuh. Data sekunder didapat dari pemilik dan karyawan Laguna Family Karaoke Di Sungai Penuh.

Teknik pengumpulan data yang digunakan dalam penelitian ini berupa penelitian pustaka (library research) yakni dengan pengambilan data yang dilakukan dengan membaca buku-buku, literatur-literatur serta tulisan ilmiah yang berkaitan dengan masalah yang dibahas. Penelitian lapangan (Field Research) yaitu pengumpulan data untuk memperoleh data primer dengan cara melakukan penelitian langsung di lapangan yaitu langsung kepada konsumen yang menggunakan jasa Laguna Family Karaoke di Sungai Penuh. Definisi operasional adalah aspek penelitian yang memberikan informasi kepada kita tentang bagaimana caranya mengukur variabel.

Penelitian ini terdapat tiga variabel bebas (X) dan satu variabel terikat (Y).

a. Kepuasan Konsumen (Y), adalah perasaan seseorang yang merupakan akibat dari perbandingan performance produk dan jasa dari Laguna Family Karaoke di Sungai Penuh yang diterima dengan yang diharapkan oleh konsumen.

b. Harga (X1), adalah biaya yang dikeluarkan oleh konsumen untuk dapat menggunakan produk dan jasa Laguna Family Karaoke di Sungai Penuh.

c. Kualitas Pelayanan (X2), kualitas pelayanan yang dimaksud adalah suatu kondisi dimana produk (jasa) Laguna Family Karaoke mampu memenuhi kebutuhan bagi yang menggunakan produk (jasa) Laguna Family Karaoke.

d. Lokasi (X3), lokasi adalah tingkat keunggulan yang diharapkan dapat memenuhi keinginan konsumen .

\section{Alat Analisis Data}

1. Regresi Linier Berganda`

Analisis kuantitatif dilakukan dengan menggunakan statistik untuk data yang memerlukan pengukuran. Analisis kuantitatif bertujuan untuk mengetahui pengaruh variabel independen terhadap variabel dependen. Dalam penelitian ini analisis statistik menggunakan Analisis Regresi Berganda:

$\mathrm{Y}=\alpha+\beta 1 \mathrm{X} 1+\beta 2 \mathrm{X} 2+\beta 2 \mathrm{X} 3+e$

2. Koefisien Determinasi (KD)

Koefisien determinasi (R2) pada intinya mengukur seberapa jauh kemampuan model dalam menerangkan variasi variabel independen. Nilai koefisien determinasi adalah antara nol dan satu.

Rumus :

$\mathrm{Kd}=\mathrm{r}^{2} \mathrm{X} 100 \%$

3. Uji Hipotesis

a. Uji F hitung, uji pengaruh simultan digunakan untuk mengetahui apakah variabel independen secara simultan mempengaruhi variabel independen (Ghozali, 2006).

b. Uji t hitung, yaitu untuk mengetahui pengaruh antara variabel-variabel yang digunakan itu berarti (signifikan) atau tidak. Untuk menguji keberartiannya itu melalui hipotesa, dimana uji ini menggunakan rumus (Sumodiningrat: 2007). 


\section{Hasil}

Tabel 1

Analisis Deskriftif Distribusi Frekuensi Variabel Kepuasan Konsumen Pada Laguna Family Karaoke Di Sungai Penuh

\begin{tabular}{llrrr}
\hline No & \multicolumn{1}{c}{ Indikator } & Rata rata skor & TCR (\%) & Ket \\
\hline 1 & Kepuasan Jasa Secara Menyeluruh & 3,93 & 78,6 & Cukup Baik \\
2 & Merekomendasikan kepada pihak lain & 4,02 & 80,4 & Baik \\
3 & Menggunakan jasa kembali & 3,84 & 76,8 Cukup Baik \\
& Rata-rata variabel & 3,93 & 78,6 Cukup Baik \\
\hline
\end{tabular}

Sumber: data olahan

Berdasarkan tabel diatas tergambar bahwa Kepuasan Konsumen Pada Laguna Family Karaoke Di Sungai Penuh berada pada kriteria cukup baik dengan rata-rata skor sebesar 3,93 dan tingkat capaian sebesar 78,6\%. Hal ini bermakna Kepuasan Konsumen pada Laguna Family Karaoke Di Sungai Penuh sudah bagus.

Tabel 2

Analisis Deskriftif Distribusi Frekuensi Variabel Harga Pada Laguna Family Karaoke Di Sungai Penuh

\begin{tabular}{|c|c|c|c|c|}
\hline No & Indikator & Rata-rata skor & TCR (\%) & Ket \\
\hline 1 & Keterjangkauan Harga & 3,88 & 78 & Cukup Baik \\
\hline 2 & Harga Sesuai Kemampuan atau daya saing & 3,99 & 79,8 & Cukup Baik \\
\hline 3 & Kesesuaian Harga Dengan Kualitas Produk & 3,28 & 65,6 & Cukup Baik \\
\hline \multirow[t]{2}{*}{4} & Kesesuaian Harga Dengan Mamfaat & 3,73 & 74,6 & Cukup Baik \\
\hline & Rata-rata variabel & 3,72 & 74,4 & Cukup Baik \\
\hline
\end{tabular}

Sumber: data olahan

Berdasarkan tabel diatas tergambar bahwa variabel harga pada Laguna Family Karaoke Di Sungai Penuh berada pada kriteria cukup baik dengan rata-rata skor sebesar 3,72 dan tingkat capaian sebesar 74,4. Hal ini bermakna harga pada Laguna Family Karaoke Di Sungai Penuh sudah baik.

Tabel 3

Analisis Deskriftif Distribusi Frekuensi Variabel Kualitas Pelayanan Pada Laguna Family Karaoke Di Sungai Penuh

\begin{tabular}{lllll}
\hline No & Indikator & Rata-rata skor & TCR $(\boldsymbol{\%})$ & Ket \\
\hline 1 & Tangibles (berwujud) & 3,87 & 77,4 & Cukup Baik \\
2 & Realibility (kehandalan) & 3,90 & 78 & Cukup Baik \\
3 & Responsivess (ketanggapan) & 4,16 & 83,2 & Baik \\
4 & Assurance (jaminan) & 3,90 & 78 & Cukup Baik \\
5 & Emphaty (empati) & 3,93 & 78,6 & Cukup Baik \\
& Rata-rata variabel & 3,95 & 79 & Cukup Baik \\
\hline
\end{tabular}

Sumber: data olahan

Berdasarkan tabel diatas tergambar bahwa kualitas pelayanan pada Laguna Family Karaoke Di Sungai Penuh berada pada kriteria cukup baik dengan rata-rata skor sebesar 3,95 dan tingkat capaian sebesar 79\%. Hal ini bermakna kualitas pelayanan pada Laguna Family Karaoke Di Sungai Penuh sudah baik.

Tabel 4

Analisis Deskriftif Distribusi Frekuensi Variabel Lokasi Pada Laguna Family Karaoke Di Sungai Penuh

\begin{tabular}{llccc}
\hline & Indikator & Rata-rata skor & TCR (\%) & Ket \\
\hline 1 & Akses & 3,93 & 78,6 & Cukup Baik \\
2 & Visabilitas & 3,67 & 73,4 & Cukup Baik \\
3 & Lalu lintas (traffic) & 3,62 & 72,4 & Cukup Baik \\
4 & Lingkungan & 3,54 & 70,8 & Cukup Baik \\
5 & Kompetensi & 3,62 & 72,4 & Cukup Baik \\
& Rata-rata variabel & 3,67 & 73,4 & Cukup Baik \\
\hline
\end{tabular}

Sumber: data olahan

Berdasarkan tabel diatas tergambar bahwa lokasi pada Laguna Family Karaoke Di Sungai Penuh berada pada kriteria cukup baik dengan rata-rata skor sebesar 3,67 dan tingkat capaian sebesar 73,4\%. Hal ini bermakna lokasi pada Laguna Family Karaoke di Sungai Penuh sudah baik. 
Tabel 5

Analiss Regresi Linier Berganda Pengaruh Harga, Kualitas Pelayannan dan Lokasi Terhadap Kepuasan Konsumen Secara Parsial Pada Laguna Family Karaoke Di Sungai Penuh Unstandardized Coefficients Standardized Coefficients

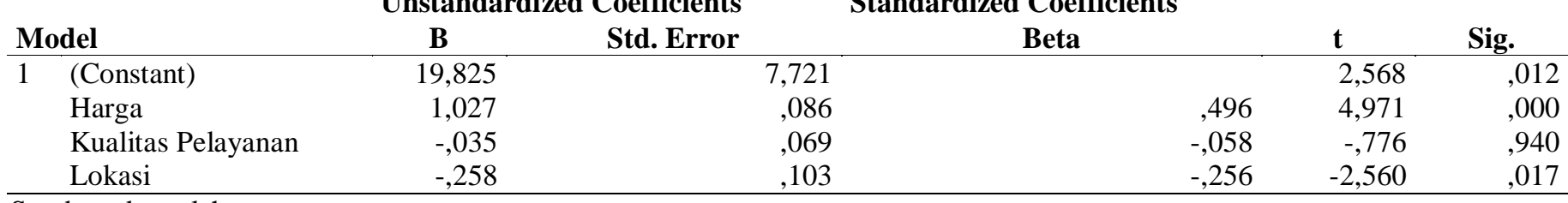

Sumber: data olahan

Persamaan regresi sebagai berikut :

$\mathrm{Y}=19,825+1,027 \mathrm{X} 1+(-0,035) \mathrm{X} 2+(-0,258) \mathrm{X} 3+\varepsilon$

1. Koefisien regresi harga (X1) terhadap Kepuasan Konsumen (Y) adalah positif 1,027 dan signifikan 0,000 (lebih kecil dari 0,05), maksudnya atau semakin baik Harga maka akan sangat mempengaruhi Kepuasan Konsumen(Y) pengguna jasa Laguna Family Karaoke di Kota Sungai Penuh

2. .Koefisien regresi Kualitas Pelayanan (X2) terhadap Kepuasan Konsumen (Y) adalah Negatif (-0, 035) dan signifikan 0,940 (lebih besar dari 0,05), maksudnya adalah Kualitas poelayanan tidak mempengaruhi Kepuasan Konsumen (Y) pengguna jasa Laguna Family Karaoke di Kota Sungai Penuh

3. Koefisien regresi Lokasi (X3) terhadap Kepuasan Konsumen (Y) adalah Negatif (-0, 258) dan signifikan 0,017 (lebih kecil dari 0,05), maksudnya adalah semakin tidak baiknya Lokasi maka akan berpengaruh terhadap semakin rendahnya tingkat Kepuasan Konsumen (Y) pengguna jasa Laguna Family Karaoke di Kota Sungai Penuh

Tabel 6

Pengaruh Harga, Kualitas Pelayannan dan Lokasi Terhadap Kepuasan Konsumen Secara Simultan Pada Laguna Family Karaoke di Sungai Penuh

\begin{tabular}{|c|c|c|c|c|c|c|}
\hline & Model & Sum of Squares & Df & Mean Square & $\mathbf{F}$ & Sig. \\
\hline \multirow[t]{3}{*}{1} & Regression & 851,172 & 3 & 283,724 & 8,461 &, $000^{\mathrm{b}}$ \\
\hline & Residual & 2548,516 & 76 & 33,533 & & \\
\hline & Total & 3399,688 & 79 & & & \\
\hline
\end{tabular}

Sumber: data olahan

Uji ANOVA atau $F$ tes ternyata di dapat $f_{\text {hitung }} 24,686$ berdasarkan perhitungan diatas maka dapat diputuskan sebagai berikut: dimana $\mathrm{f}_{\text {hitung }}>\mathrm{f}_{\text {tabel }}$ yaitu 24,686>2,58 dan 0,000<0,05, maka Ha diterima dan Ho ditolak dimana artinya Harga,Kualitas Pelayanan Dan Lokasi secara bersama sama berpengaruh Terhadap Kepuasan KonsumenLaguna Family Karaoke Sungai Penuh. Hipotesis Keempat dapat diterima

Tabel 7

Besar Pengaruh Harga, Kualitas Pelayanan dan Lokasi Terhadap Kepuasan Konsumen pada Laguna Family Karaoke Di Sungai Penuh

\begin{tabular}{|c|c|c|c|c|}
\hline Model & $\mathbf{R}$ & R Square & Adjusted R Square & Std. Error of the Estimate \\
\hline 1 &, $500^{\mathrm{a}}$ &, 250 & ,221 & 5,791 \\
\hline
\end{tabular}

Sumber: data olahan

Berdasarkan tabel diatas maka dapat disimpulkan bahwa besarnya pengaruh Harga,Kualitas Pelayanan Dan Lokasi Terhadap Kepuasan KonsumenLaguna Family Karaoke Sungai Penuh adalah bahawa Nilai R square di atas akan dirubah dalam bentuk persen guna mengetahui seberapa besarnya sumbangan Harga, kualitas Pelayanan dan Lokasi terhadap kepuasan Konsumen Laguna Family Karaoke Sungai Penuh. Nilai $\boldsymbol{R}^{\mathbf{2}}$ sebesar ,250 jika dipersenkan menjadi $25 \%$. Artinya, sumbangan Harga, kualitas Pelayanan dan Lokasi secara bersama-sama berpengaruh terhadap kepuasan Konsumen Laguna Family Karaoke Sungai Penuh sebesar 25\%. Sisanya sebesar $75 \%$ dipengaruhi oleh variabel lain yang tidak dapat dibahas dalam penelitian ini.

\section{Simpulan}

1. Terdapat pengaruh antara Harga terhadap Kepuasan Konsumen yang dibuktikan $t$ hitung $>$ dari $t$ tabel yang mana 7,456 > 2,021 dan signifikan 0,000 < 0,05. Dengan demikian maka berdasarkan kriteria uji signifikan, Ha diterima dan Ho ditolak artinya bahwa harga berpengaruh signifikan dan positif TerhadapKepuasan KonsumenLaguna Family Karaoke. 
2. Tidak Terdapat pengaruh antara Kualitas Pelayanan terhadap Kepuasan Konsumen yang dibuktikan oleh $\mathrm{t}_{\text {hitung }}<$ dari $t_{\text {tabel }}$ yang mana $-0,918<2,021$ dan signifikan 0,363 $>0,05$. Dengan demikian maka berdasarkan kriteria uji signifikan, Ha ditolak dan Ho diterima artinya bahwa Kualitas Pelayanantidak berpengaruh terhadap TerhadapKepuasan KonsumenLaguna Family Karaoke Sungai Penuh

3. Terdapat pengaruh antara Lokasi terhadap Kepuasan Konsumen yang dibuktikan oleh $\mathrm{t}_{\text {hitung }}<$ dari $\mathrm{t}_{\text {tabel }}$ yang mana $-2,371>2,021$ dan signifikan 0,020 < 0,05. Dengan demikian maka berdasarkan kriteria uji signifikan, Ha diterima dan Ho ditolak artinya bahwa Lokasi berpengaruh signifikan terhadap Kepuasan Konsumen Laguna Family Karaoke Sungai Penuh

4. Secara bersama sama terdapat pengaruh antara Harga,Kualitas Pelayanan Dan Lokasi TerhadapKepuasan KonsumenLaguna Family KaraokeSungai Penuh dibuktikan dengan dapat $\mathrm{f}_{\text {hitung }}$ 24,686berdasarkan perhitungan diatas maka dapat diputuskan sebagai berikut: dimana $f_{\text {hitung }}>f_{\text {tabel }}$ yaitu 24,686>2,58 dan 0,000 < 0,05, maka Ha diterima dan Ho ditolak dimana artinya Harga,Kualitas Pelayanan Dan Lokasi secara bersama sama berpengaruh Terhadap Kepuasan Konsumen Laguna Family Karaoke Sungai Penuh.

5. Besarnya sumbangan Harga, Kualitas Pelayanan Dan Lokasi Terhadap Kepuasan Konsumen Laguna Family Karaoke Sungai Penuh Nilai $\boldsymbol{R}^{2}$ sebesar 0,494 jika dipersenkan menjadi 49,4\%. Artinya, sumbangan Harga, kualitas Pelayanan dan Lokasi secara bersama-sama berpengaruh terhadap kepuasan Konsumen Laguna Family Karaoke Sungai Penuh sebesar 49,4\%. Sisanya sebesar 50,56 \% dipengaruhi oleh variabel lain yang tidak dapat dibahas dalam penelitian ini.

\section{Daftar Pustaka}

Alma, Buchory. Dan Saladin, Djalim. 2010. Manajemen Pemasaran : Ringkasan Praktis, Teori Aplikasi dan Tanya Jawab. Bandung : CV. Linda Karya

Augusty Ferdinand. 2006. Metode Penelitian Manajemen. Semarang: Badan Penerbit Universitas Diponegoro.

Amirullah. 2015. Pengantar Manajemen, Jakarta : Mitra Wacana Media

Arikunto, S, 2013. Prosedur Penelitian. Suatu Pendekatan Praktik. Jakarta: Rineka Cipta.

Assuari Sofjan.2013. Manajemen Pemasaran. Jakarta. : Rajawali Pers

Barnes, J. G. 2003. Secret Of Customer Relationship Management (Rahasia Manajemen Hubungan Pelanggan) Yogyakarta: Andi

Basu Swasta dan Irawan, 2005 Manajemen Pemasaran. Yogyakarta

Ben M. Enis, 2007. Manajemen Pemasaran dan Pemasaran Jasa. Bandung: Alfabeta

Cronin. Joseph Jr, Steven A. Taylor, 1992, Measuring Service Quality : A Rexamination and Extension, Jornal Of Marketing. Vol.56

Dita amanah (2010) "Pengaruh Harga dan Kualitas Produk terhadap Kepuasan Konsumen pada Majestyk bakery \& Cake Shop Cabang H.M Yamin Medan.

Emzir. 2009. Metodologi Penelitian Pendidikan: Kuantitatif dan Kualitatif. Jakarta: Rajawali Pers

Engel,. et.al., 1994, Consumer Behavior, Jilid 1, Alih Bahasa Budiyanto, Penerbit : Binarupa Aksara, Jakarta.Penerbit : Erlangga, Jakarta

Eswika Linasari, 2015, Pengaruh Kualitas Pelayanan Terhadap Kepuasan Konsumen Pada Dealer PT. Ramayana Motor Sukoharjo.

Gitosudarmo, Indriyo. 2000. Manajemen Pemasaran. Edisi I, BPFE-UGM, Yogyakarta.

Haryogi, W.P. Dan Sri, S.I, 2015 Pengaruh Kualitas Produk Dan Kelompok Acuan Terhadap Keputusan Pembelian Sepeda Motor Suzuki Satria F150. Jurnal Of Research In Economics And Management, (Jurnal Riset Ekonomi dan Manajemen,Volume 15, No. 2, Juli - Desember (Semester II) 2015, Halaman 262-279.

Hasibuan, Malayu. 2006 Manajemen Dasar, Pengertian dan Masalah, PT Bumi Aksara:Jakarta

Indoskripsi. 2009. http://www.one.indoskripsi.com. Diakses 8 Juli 2009. Kotler,

Philip dan Armstrong. 2007. Dasar-dasar Pemasaran. Edisi Kesembilan, Cetakan Kedua, PT. Indeks, Jakarta.

Kotler, P. 2002. Marketing Management, Millenium Edition North Western, Prentice Hall Inc. University New Jersey.. 2009. Manajemen Pemasaran. Erlangga. Jakarta

Kotler, P. dan G. Armstrong. 2008. Prinsip-prinsip Pemasaran. Edisi 12. Erlangga.

Jakarta.. 2012. Prinsip-prinsip Pemasaran. Edisi 13. Erlangga. Jakarta.

Kotler, P., dan Keller, K.L., 2009, Manajemen Pemasaran, PT. Indeks, Jakarta.

Lupiyoadi Hamdani.2006. Manajemen Pemasaran Jasa Edisi Kedua.Salemba Jakarta : Empat.

Luther, Gulick. 1960. Paper on the Science of Administration. Routledge, Reprint edition

Majestykbakery. (2009). http://www.majestykbakery.co.id. Diakses 8 Juli 2009.

Malhotra.2005. Riset Pemasaran. Jilid I. Edisi 4. Jakarta: Indeks Kelompok Gramedia

Mursid, 2014. Managemen Pemasaran. Jakarta:Bumi Aksara

Moenir 2002 Manajemen Pelayanan Umum di Indonesia. Jakarta: PT. Bumi Aksara 
Philip William J. Shultz (dalam buku Prof. Dr. H. Buchari Alma) "Manajemen pemasaran dan pemasaran jasa". Cetakan-7, 2005, p130)pupuklopedia.blogspot.com/2014/06/pupuk-urea.html?m=1

Rama Joko Darmawan, Waynerama5@ gmail.com, Budhi Satrio 2017, Pengaruh Harga,Kualitas Pelayanan dan Lokasi Terhadap Kepuasan Konsumen Pada Apotek Takavi.

Sihabudin (2015) "Pengaruh Kualitas Produk dan Promosi Terhadap Citra Merek Handphone Samsung. Jurnal Manajemen \& Bisnis, ISSN 2528-0597, Vol. 1 No. 1, 2015.

Sugiyono, 2008. Metode Penelitian Kuantitatif Kualitatif dan R\&D. Bandung Alfabeta

Statistka Untuk Penelitian. CV Alfabeta. Bandung. 2011. Metode Penelitian Kuantitatif Kualitatif dan R \& D. Cetakan13.CV Alfabeta.Bandung.

Sugiyono.2009. Statistika Untuk Penelitian. Bandung :Alfabeta

Supardi. 2005. Metodologi Penelitian Ekonomi dan Bisnis. Yogyakarta:UII Press

Supranto, 2001, Pengukuran Tingkat Kepuasan Pelanggan Untuk Menaikkan Pangsa Pasar, Penerbit Rineka Cipta, Jakarta, 230,243

Sekaran, Uma. (2011). Metode Penelitian Untuk Bisnis. Jakarta: Salemba Empat

Sutopo.2014.Analisis Pengaruh Kualitas Pelayanan, Promosi dan Lokasi Terhadap Kepuasan Konsumen (studi kasus pada PT.Maharani Tri Utama Mandiri Cabang Semarang)

Tjiptono, F. 1997. Strategi Pemasaran. Edisi Kedua. Cetakan Pertama. Andi Off set. Yogyakarta. dan G. Chandra. 2012.Pemasaran Strategik. Edisi Dua. Andi Offset. Yogyakarta.

Tjipton, Fandy. 2007. Strategi Pemasaran Edisi Kedua. Yogyakarta : Andi.

Tse dan Wilson. 2004. Manajemen Jasa Terpadu. Ghalia Indonesia.

Umi Narimawati. 2008 Metodologi Penelitian Kualitatif dan Kuantitatif, Teori dan Aplikasi. Bandung: Agung Media

Fandy, Tjiptono.2007. Strategi Pemasaran Edisi Kedua. Yogyakarta : Andi.

Wilkiningtyas, 1998, Strategi Pemasaran, Mandar Maju, Bandung

Yazid.2001. Pemasaran Jasa Konsep dan Implementasi. Yogyakarta : Ekonosia Fakultas Ekonomi UII

Zeithaml. Valarie, Bitner \& Gremler. 2006.Service Marketing -Integrating Customer Focus Accross The Firm Forth Edition. New York: McGraw Hill 